PERINATAL LESSONS FROM THE PAST

\title{
Dr Christian Kielland of Oslo (1871-1941) and his straight forceps
}

\section{P M Dunn}

Arch Dis Child Fetal Neonatal Ed 2004;89:F465-F467. doi: 10.1136/adc.2003.047993

Christian Kielland, a Norwegian obstetrician, published a description of his straight forceps in 1916. Although internationally recognised as a most valuable instrument for rotation of the fetal head, for many years his instrument received little appreciation in his own country.

\footnotetext{
Correspondence to: Professor Dunn, Department of Child Health, University of Bristol, Southmead Hospital, Southmead, Bristol BS10 5BN, UK; P.M.Dunn@bristol.ac.uk

Accepted 13 December 2003
}

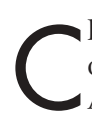
hristian Caspar Gabriel Kielland was born on 10 November 1871 in Zululand, South Africa, where his father, the Reverend Jan Olaus Kielland (1833-1898), was a missionary. His mother was Hanna Olsen (1842-1913). The family came from a long lineage of ship owners near Stavanger in West Norway. In 1874, when Christian was three, and five years before the Zulu war of 1879, the family returned to Norway. After early instruction in his father's vicarage at Brönnöysund, North Norway, Christian received his education at the Kathedralskole in Oslo, attaining the "examen atrium" (equivalent to British A levels) in 1891. He then studied medicine at Kristiania (now the University of Oslo), graduating in 1899 at the age of 28 . After a resident appointment in Gravdal Hospital in Lofoten and some locum general practice in Nordland, he returned to Oslo in 1901 to work in the surgical department of the National Hospital. In 1902, he spent two years at the maternity hospital, Fødsels-stithelsen. At the same time, he was private assistant to Professor Christian Brandt (1859-1932), the obstetrician in chief at the University Clinic, a post he held for the next $71 / 2$ years. Between 1911 and 1914, Kielland was senior registrar at the Fødsels-stithelsen in Oslo. During this period he also worked abroad on four occasions, mainly in Copenhagen, and was for several years private assistant to Livmedicus (King's physician) Egeburg. After this training, Kielland held no further formal hospital appointments, although he undertook his gynaecological surgery at the Catholic Hospital in Oslo. He had opened his own private surgery in 1903 and continued to run this and to conduct home deliveries up to the end of his life some 40 years later. $^{1-3}$

Christian Kielland (fig 1) was a member of the Norwegian Medical Society and of the Kristiania Medical Society. Although he suggested a new way of operating to correct the prolapsed uterus which was well regarded abroad, Kielland's international reputation and fame rested entirely on the forceps that carry his name. In 1908 he gave a lecture to the Surgical Society of Kristiania with the title "The delivery forceps mechanism and technique". Two years later in 1910, he demonstrated his forceps in Copenhagen and at various clinics in Germany. But it was not until 1915 during a visit to the Munich Gynecological Society at the invitation of Professor Döderlein that his forceps received the recognition they deserved. In 1916 Kielland published a full description of his forceps (fig 2) with indications for their use and his own novel method of application. His paper was based on a personal series of 352 deliveries performed during the previous seven years. ${ }^{1-3}$

The original straight Chamberlen forceps of the 17th century had been superseded by those with a pelvic curve during the 18th century. When the long curved forceps became popular, forceps rotation was deemed to be dangerous and was rarely undertaken because of the risk of vaginal lacerations and damage to the head of the fetus. As Kielland wrote in the introduction to his paper: ${ }^{4}$

"Every obstetrician knows that delivery by forceps of a head which is low in the pelvis and more or less completely rotated is an operation which can usually be performed easily. The forceps, being designed to harm neither mother nor child, effects this in a

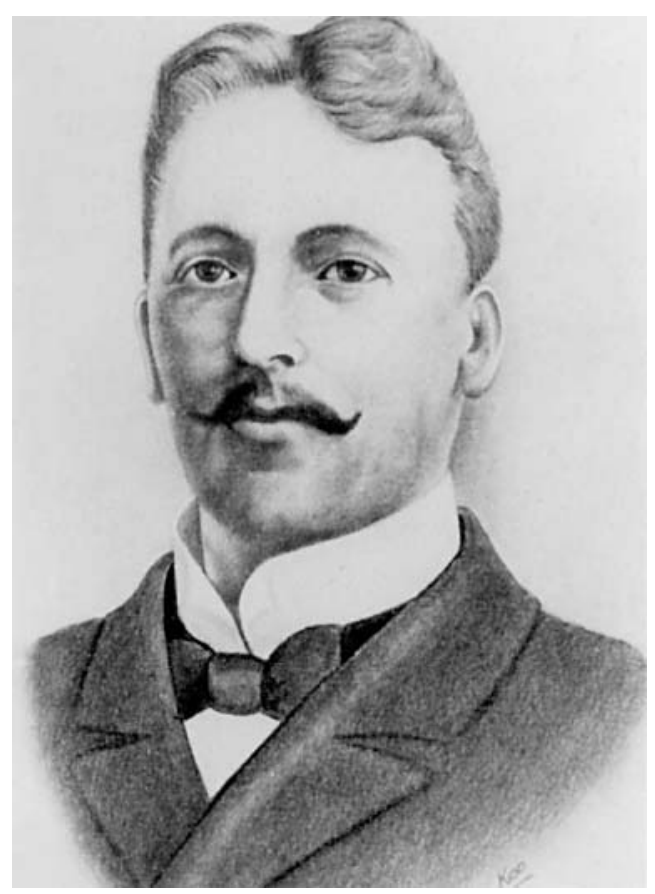

Figure 1 Christian Kielland (1871-1941). 
beautiful way. However, when the head is high in the pelvis or at the brim many other factors become operative which make the subsequent delivery very different from the typical outlet forceps ...

When the head is high it has to be pulled through a greater length of the birth canal, which is incompletely prepared. The child's head is in such a position that it cannot be grasped by the blades of the forceps in the way which is possible when the head is low and completely rotated. The forceps do not hold the head in the biparietal diameter, but over the occipital and frontal areas which cannot withstand much pressure. These factors are responsible for the difficulties which occur in such a delivery, but they do not entirely explain the amount of force required nor the resistance which is encountered. In the search for an explanation of the chief cause for the remarkable amount of force which had to be used, it was thought that traction might be in the wrong direction, because the blade of the ordinary forceps is curved to correspond with the birth canal. This type of forceps cannot be depressed sufficiently low against the perineum without the risk of damaging it or losing the good position on the foetal head when an attempt is made to exert traction in the pelvic axis ...

While there have been many forceps made with the object of obtaining an exact direction of traction, there are only a few whose purpose is to make their application easy and correct (this, as is well known, is offen difficult when the head is high). In this article it is proposed first to describe a special method of applying the forceps which results in a satisfactory hold of the foetal head, and secondly to discuss whether the exact position of the blades on the foetal head has any special influence on the delivery."

Kielland's paper ${ }^{14}$ had the title "The application of forceps to the unrotated head. A description of a new type of forceps and a new method of insertion". The forceps (fig 2) were straight and bayonet shaped with a slight and offset pelvic curve so that the axis of the curve was parallel to the axis of the handle. Another unique feature was the sliding lock associated with flat shanks, which facilitated good cephalic application even when there was a gross degree of asynclitism. The use and value of Kielland's forceps has been summarised by Hibbard $^{5}$ as follows:

"The primary purpose of his forceps was for extraction of the incompletely rotated head from the upper pelvis but subsequently they came to be used for deep transverse arrest (the commonest indication in recent times) and rotation of occipito posterior presentation, as well as face presentation and delivery of the aftercoming head in breech delivery. Kielland, in his description, reiterated the problems of proper application and traction described earlier by Tarnier and Milne Murray. He concluded that most problems when the head was high were due to a transverse position rather than a serious degree of disproportion. Previously the solution had been to apply forceps over the face and occiput. Kielland's forceps were designed to be applied in correct cephalic relationship and this necessitated a design of forceps which allowed safe application of the anterior blade. In his classical description the anterior blade is inserted upside down and then rotated through $180^{\circ}$. To allow this the area of the junction of the blade to the shank is narrower and has bevelled edges. However most obstetricians now use either

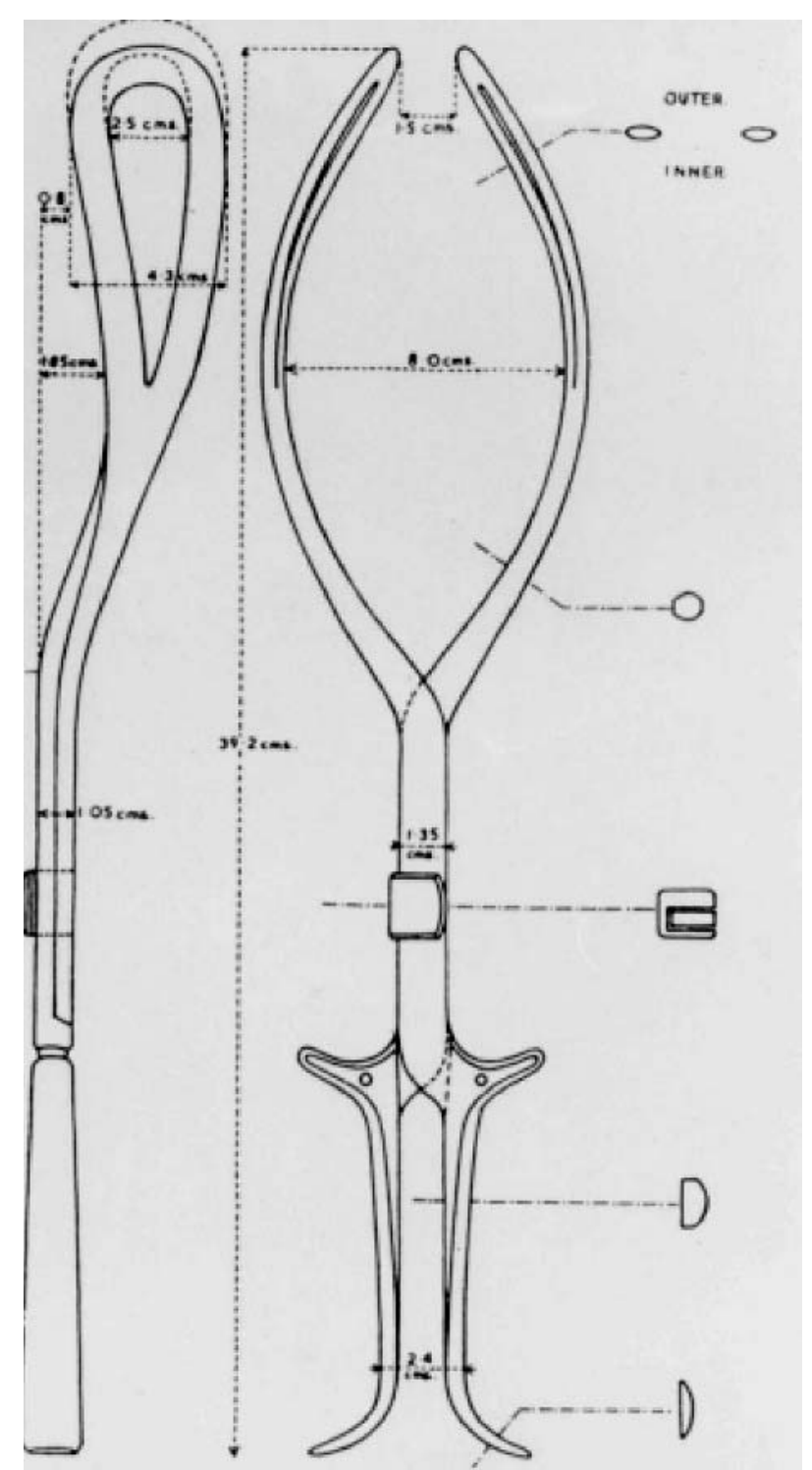

Figure 2 Kielland's forceps with their measurements.

the direct or wandering method of application in preference to the classical procedure."

His method of application of the anterior blade was made possible by the absence of a pelvic curve to the blade. Although new at the time, it actually represented the revival of a technique used by Dutch obstetricians in the 18th century for the insertion and application of the lever or vectis, as described by Bokelmann in about 1750. ${ }^{1}$ Kielland himself emphasised that the use of his forceps required more than the usual skill, particularly in accurate diagnosis of the fetal presentation and position. He also stressed that rotation of the fetal head should be undertaken before and separately from traction.

For the application of the straight forceps, an episiotomy was required. This had become possible at the beginning of the 20th century because of the arrival of effective asepsis and local and general anaesthesia, which had diminished the need to preserve the perineum intact. As the 20th century progressed, high and difficult forceps deliveries were increasingly discarded in favour of an alternative caesarean section. However, with the widespread use of epidural anaesthesia during the 1970s, deep transverse arrest became a more 
common problem, and the use of Kielland's forceps has increased considerably. ${ }^{\circ}$

Kielland's forceps found immediate favour with the medical profession abroad, and during the next quarter of a century more than 200 papers were published reporting its use. Indeed his forceps were regarded as one of the most valuable instruments in the obstetrician's armamentarium. Strangely enough this was not so in Norway. Kielland's own chief, Professor Brandt, never thought much of the instrument, preferring to use Simpson's forceps and not even mentioning Kielland's in his 1922 obstetric textbook. Indeed, they were not accepted in Norway until after Brandt's death in 1932. As one Norwegian supporter and colleague commented in 1925: “One does not get fame in one's own country and Kielland was and still is the best ever known Norwegian obstetrician".

Kielland has been described as having an impressive personality with a good sense of humour. In 1900, he married Alice Franziska Louise Traub (born in Istanbul in 1878), the daughter of Banker Henry Traub and his wife Anna Herz. They had two sons and a daughter. Kielland died in Oslo from a cerebral embolus on 18 March 1941. ${ }^{3}$ Years later in 1979, Professor Ian Donald of Glasgow wrote: "To Kielland must go the honour of making the greatest single advance in forceps design, since when little of major importance has come on the scene" ${ }^{\prime 7}$

\section{ACKNOWLEDGEMENTS}

I am grateful to Professor Marianne Thoresen of Bristol for the Norwegian translations.

\section{REFERENCES}

1 Parry JE. Kielland's forceps. London: Butterworth \& Co, 1952.

2 Speert H. Obstetrics and gynecologic milestones (illustrated). New York: The Parthenon Publishing Group, 1996:509-12.

3 Hem E, Børdal PE. Med tangen ut i verden-Christian Kielland og hans tang Tidsskr Nor Loegeforen 2001;121:1496-7.

4 Kielland $\mathbf{C}$. The application of forceps to the unrotated head. A description of a new type of forceps and a new method of insertion. (Translated from the original article in Monatsschrift für Geburtshilfe und Gynäkologie 1916;43:48-78.)

5 Hibbard BM. The obstetric forceps. London: Chameleon Press, 1992:59-60.

6 O'Dowd MJ, Phillip EE. The history of obstetrics and gynaecology. New York: Pathenon Publishing Co, 1994:148-9.

7 Donald I. Practical obstetric problems. London: Lloyd-Luke, 1979:654-60.

\section{IMAGES IN NEONATAL MEDICINE}

\section{Pachyonychia congenita}

W

have recently experienced this rare condition in a premature baby born at 25 weeks gestation. At the age of 56 days, it was noticed that he had developed odd looking fingernails (two on each hand). He did not have any other mucocutaneous abnormalities or family history of similar conditions.

A culture of his nails was reported as negative for bacterial and fungal infections, and the diagnosis of pachyonychia congenita was made on the basis of nail morphology.

Pachyonychia congenita is a group of uncommon hereditary keratin disorders characterised by hypertrophic nail dystrophy and associated ectodermal features. ${ }^{1}$ However, it can be manifested with only nail affection. ${ }^{2}$ The nails are thickened and tubular, projecting upward at the free edge to form a conical roof over a mass of subungual keratotic debris (fig l).

W M El-Matary

Neonatal Unit, Glan Clwyd Hospital, Rhyl, North Wales LL18 5UJ, UK

I Barnard

CDC, Clatterbridge Hospital, Clatterbridge Road, Bebington, Wirral CH63 4JY, UK; welmatary@yahoo.com

\section{REFERENCES}

1 Munro CS. Pachyonychia congenita: mutations and clinical presentations. $\mathrm{Br} J$ Dermatol 2001; 144:929-30.

2 Pryce DW, Verbov JL. A family with pachyonychia congenita affecting the nails only. Clin Exp Dermatol 1994;19:521-2.

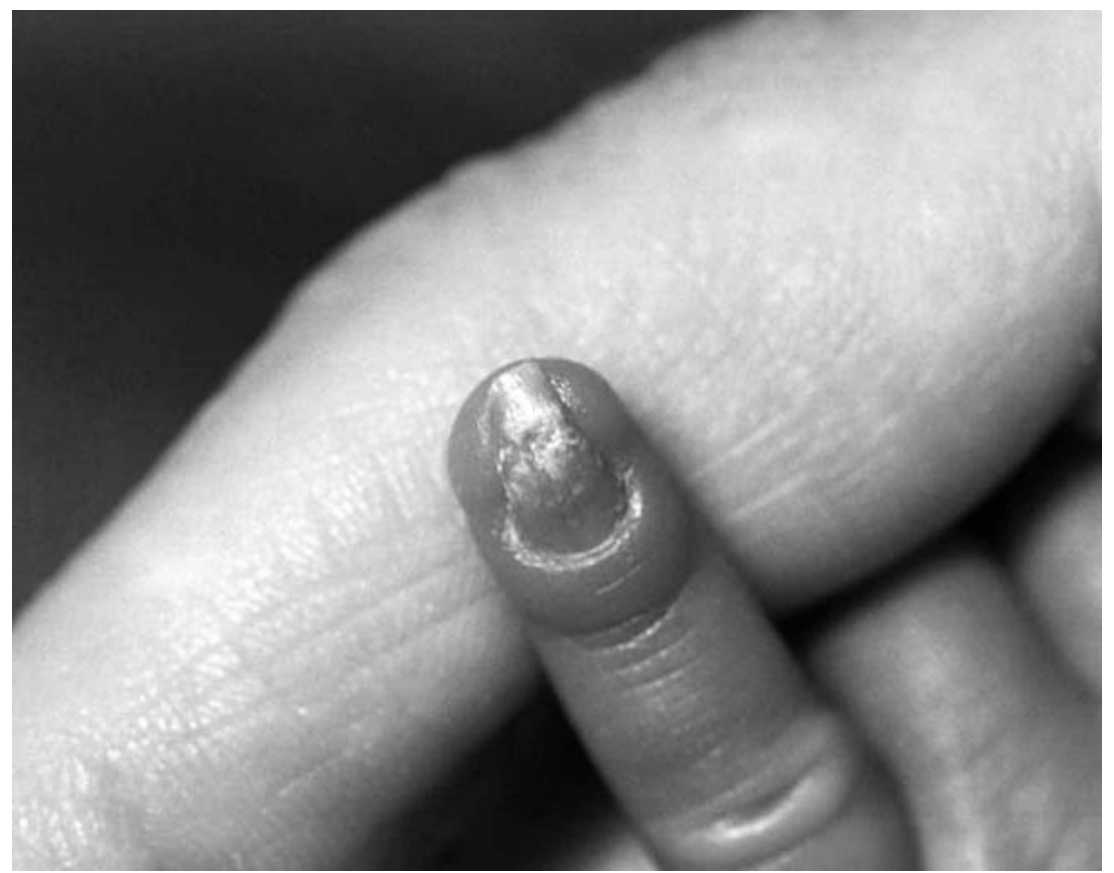

Figure 1 Thickened nail characteristic of pachyonychia congenita. 